NDT and E International, 36 (7), pp. 471-477, 2003

\title{
Observations of Acoustic Emission activity during gear defect diagnosis
}

\section{Tim Toutountzakis, David Mba}

School of Engineering, Cranfield University, Bedfordshire. MK43 0AL, UK; Tel +44 (0) 1234754681, Fax: +44 (0) 1234-751566.

E-mail: T.Toutountzakis.2002@Cranfield.ac.uk and d.mba@cranfield.ac.uk

\begin{abstract}
It is widely recognised that Acoustic Emission (AE) is gaining ground as a NonDestructive Technique (NDT) for health diagnosis on rotating machinery. The source of $\mathrm{AE}$ is attributed to the release of stored elastic energy that manifests itself in the form of elastic waves that propagate in all directions on the surface of a material. These detectable AE waves can provide useful information about the health condition of a machine. This paper reports on part of an ongoing experimental investigation on the application of acoustic emission for gear defect diagnosis. Furthermore, the possibility of monitoring gear defects from the bearing casing is examined. It is concluded that $\mathrm{AE}$ offers a complimentary tool for health monitoring of gears.
\end{abstract}

Keywords: Acoustic Emission, gear defect diagnosis, micro pitting, pitting, 


\section{Introduction}

Measurement of high frequency Acoustic Emissions (AE) has become a viable technique in the condition monitoring of many types of rotating machinery [1-5]. On real operational machinery it is often only practical to take AE measurements from nonrotating members, at or on the bearing housing. Consequently, AE signals originating from any component other than the bearing will incur significant attenuation to an $\mathrm{AE}$ receiving sensor attached on the bearing housing. Furthermore, the AE signal will be further colored by the characteristic frequency response of the AE transducer itself. In light of these factors, interpretation of the $\mathrm{AE}$ signals is not trivial. Frequencies associated with AE activity cover a broad frequency range of between $20 \mathrm{KHz}$ to $1 \mathrm{MHz}$.

Publications of vibration analysis to gear fault diagnosis are widely available and the subject has been investigated for over four decades. Most gear failures are a result of bending and surface fatigue. Drosjact et. al [6] attempted to relate changes in gear defect vibration frequencies with the actual physical mechanism that caused such a change. It was postulated that changes in tooth thickness due to the presence of pits cause modifications in the Hertzian compliance. In addition, it was commented that pitting caused instantaneous changes in Hertzian stiffness which generated a Hertzian impact as a direct result of the sudden velocity differences between the pinion and the wheel. Furthermore, micro pitting was identified as a source of increased vibrations. Micro pitting is linked with the initiation of other failure modes such as pitting, scuffing, and flank initiated bending failures. Traditional gear design has addressed pitting resistance as 
the limiting process for gear life but more recently micro pitting has received considerable attention especially in conditions of low film thickness where it is the dominant life limitations[7]. Pitting is a phenomena associated with rolling contacts.

Al-Balushi et al [8]employed energy-based methods for diagnosis of spurs gears in a back-to-back gearbox. The test rig was run to failure for 40hrs. Analysis of relative energy was used for diagnosis and compared with statistical methods (Kurtosis etc). More specifically the square root of energy index, cumulative energy index and cumulative square root of energy index were computed. Test results related AE energy levels to a broken teeth and signs of pitting. It is interesting to note that no torque/load vales were presented, furthermore, it would be expected that should stress levels be large enough to cause tooth failure within 40-hours, pitting across the entire gear teeth would be evident. The results were also compared with vibration data for a helicopter gearbox. Al-Balushi author suggested that $\mathrm{AE}$ technique was advantageous in relation to the vibration method for identification and location of a defect. There was no specific information on the characteristics of the AE sensors employed, however, AE signatures were band pass filtered between range $40 \mathrm{KHz}$ to $60 \mathrm{KHz}$.

Tandon et al. [9] applied AE to spur gears in a back-to-back gearbox test-rig. The speed of the motor was kept constant at 1000rpm while the load varied during the test. A jet oil lubrication system was employed for lubrication. The AE sensor employed had a resonant frequency of $375 \mathrm{KHz}$. Simulated pits of constant depth $(500 \mu \mathrm{m})$ and variable diameter (250/350/450/550/1100 and $2200 \mu \mathrm{m})$ were introduced by spark erosion on the 
pitch line. Three AE parameters were measured; energy, peak amplitude and AE counts. Tandon concluded that the AE parameters increased as the defect size (diameter of pit) and the load increased. The AE measurements indicated a sharp increase when the defect size was around 500 $\mu \mathrm{m}$ whereas vibration data showed a comparable increase in activity when the defect size was more than $1000 \mu \mathrm{m}$, indicating an advantage of AE over vibration for early detection of defects in gears.

Sentoku [10] undertook investigations into the application of AE to spur gear defect diagnosis under forced lubrication conditions at rotational speeds of $800 \mathrm{rpm}$ and 992rpm. An AE sensor was placed on a gear wheel and the detected AE signature was transmitted across a mercury slip ring. The resonant frequency of the AE sensor was 350 KHz. In addition, a strain gauge was placed on the root of the tooth in order to related AE activity to changes in the tooth root strain values. During tests the surface roughness of the tooth was measured at appropriate times, as was the pitting size. No faults were seeded, and natural pitting occurred during the course of the test. During early stages of the test (number of cycles $5 \times 10^{4}$ to $10^{6}$ ), Sentoku observed no changes in $\mathrm{AE}$ amplitude, rather it was noted that the AE signal became smoother. At that point, visual inspection confirmed that there was no pitting on the gear tooth surface. As the number of cycles increased $\left(11 \times 10^{5}\right.$ to $\left.18 \times 10^{5}\right) \mathrm{AE}$ amplitude increased, as did the pitting area ratio. It was concluded that AE amplitude and energy increased with an increase in pitting.

Miyachika et al [11] performed a bending fatigue test using three different gears with common module $(4 \mathrm{~mm})$, pressure angle $\left(20^{\circ}\right)$ and number of teeth (18). Two sets of 
gears were made of SC415 steel, had a face width of 10mmand were case hardened to a depth $0.9 \mathrm{~mm}$ and $1.8 \mathrm{~mm}$ (Hardness, Hv 550). A third gear set was normailsed with a face width 8mm. An AE sensor was placed on the gear and AE signatures were filtered between $200 \mathrm{KHz}$ to $1000 \mathrm{KHz}$. For the two case-hardened gears, an increase in event counts and cumulative event counts was observed just before initiation of a tooth crack. For the normalized gear not such an observation was made. Furthermore, on case hardened gears an increase in cumulative event count increased with crack growth to a specific depth of hardness, after which the rate was almost constant. The peak amplitude of the case-hardened gears was also higher than the one from the normalized ones.

Singh et al [12] undertook experiments on two different types of gearboxes to investigate simulated pitting on the pitch line of a gear tooth using an EDM process. For both set-ups an $\mathrm{AE}$ sensor with resonant frequency $280 \mathrm{KHz}$ was employed. In addition, an accelerometer was also used for comparative purposes. It was interesting to note that both the accelerometer and AE sensor were placed on the gearbox casing. The first experiment employed a "Generator Drive Offset Quill” which is used on some UH-1 helicopters. The gear ratio was 41:55 and the speed was maintained constant at 1400rpm. A simulated pit was introduced at the pitch line (using EDM) in just one tooth, with dimensions $1.25 \mathrm{~mm}$ depth and 1.25mm diameter. During background noise test it was observed that a reduction in rotational speed to 920rpm resulted in a decrease in background $\mathrm{AE}$ amplitude. An increase in speed also increased the background noise levels. The second set-up was a back-to-back gearbox with gear ratio 1.5 (42/28 teeth) and speeds of 1775rpm and 2662rpm. In this set-up no fault was introduced. Pitting started to appear 
after about half an hour. Periodic AE activity was observed and it was concluded that the AE activity resulted from contact over the pitted region. Singh et al concluded that AE provided early pit detection over vibration monitoring.

Yet further investigations were undertaken by Singh et al [13] to establish the applicability of $\mathrm{AE}$ to crack growth detection and investigate the transmissibility of $\mathrm{AE}$ signals across several mechanical interfaces in the gearbox. The first part of the investigation centered on single tooth bending tests. The load on the tooth varied sinusoidally at $40 \mathrm{~Hz}$ frequency and the number of cycles recorded. The amplitude of the AE signal was monitored in real time and stored electronically until breakage occurred. During the bending test an accelerometer was also used to monitor vibration level. The test showed that $\mathrm{AE}$ signal could detect crack initiation and growth while the accelerometer could detect the crack growth only in the later stages.

The second part of the experiment involved accessing the transmissibility of AE within the gearbox. Several transmission paths were investigated and lead pencil breaks were used to simulate AE activity in the gears. Tests were untaken at varying torque levels and it was observed that at light loads greater attenuation was observed relative to heavily loaded conditions. In addition, it was noted that at high loads the rate of attenuation remained fairly constant. Attenuation of $19 \mathrm{~dB}$ was observed across the gear mesh and a total loss of up to $45 \mathrm{~dB}$ was noted from the gear mesh to the bearing housing. This loss was an accumulation of losses across individual interfaces, e.g., shaft-spline interface. 
The papers reviewed clearly demonstrate that AE has the potential of becoming a useful diagnostic complimentary tool for condition monitoring of gears.

\section{Experimental set-up}

The test-rig employed consisted of two identical oil-bath lubricated gearboxes, connected in back-to-back arrangement, see figure 1 . The gear set employed were made of 045M15 steel, with no heat treatment, employed a module of $3 \mathrm{~mm}$, a pressure angle of $20^{\circ}$, surface roughness of between $2-3 \mu \mathrm{m}$ and had 49 and 65 teeth. Each gearbox had four identical ball bearings. A simple mechanism that permitted a pair of coupling flanges to be rotated relative to each other, and locked in position, was employed to apply torque to the gears. The effect of this process was to twist the shafts and lock in the torque within the loop of the back-to-back gearbox. The effective torque loading was a combination of the static and dynamic (inertia) loading. A fixed torque was used for all experimental investigations. The motor used to drive the gearbox was a variable speed (2.2Kwatts) motor with a maximum rotational speed of 2820rpm. 


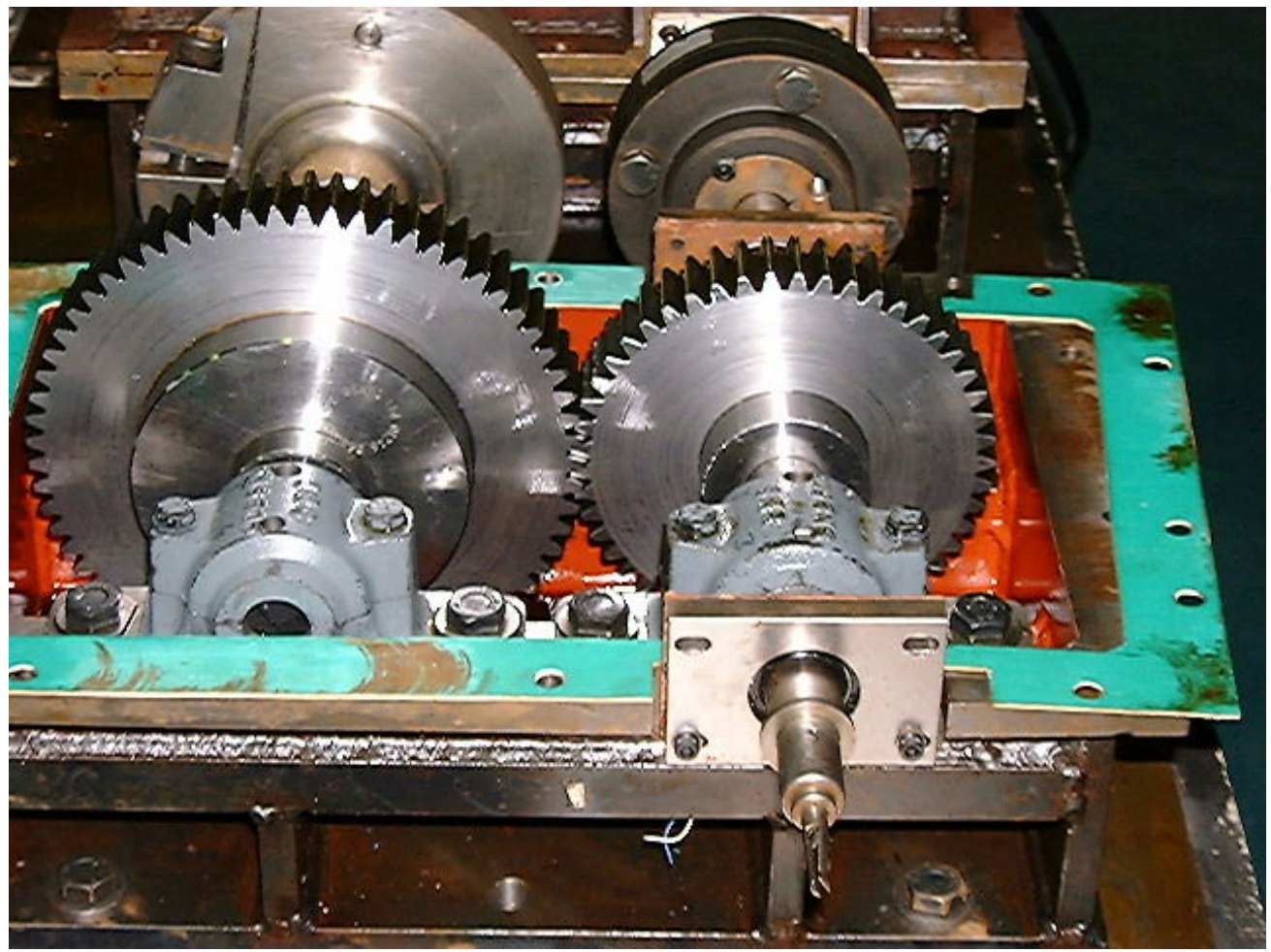

\section{Figure 1 Test-rig gearbox arrangement}

The AE sensors used for this experiment were resonant type sensors with a relative flat response in the region between $150 \mathrm{KHz}$ to $750 \mathrm{KHz}$ (Nano-30 model, 'Physical Acoustics Corporation'). One sensor was placed on the driven gear wheel (49 teeth) and the other on the ball-bearing casing of the driven gear wheel shaft. The cable connecting the sensor placed on the gear with the pre-amplifier was feed into the shaft and connected to a slip rig, see figure 2. This arrangement allowed the AE sensor to be placed as close as possible to the gear teeth. Both sensors were held in place with mechanical fixtures. A PH-12 slip rig manufactured by 'IDM Electronics Ltd' was employed. The slip rig could accommodate up to 12 channels and used silver contacts. The cooling Air Pressure for 
the slip ring was $1.4 \mathrm{~kg} / \mathrm{cm}^{2}$, see figure 3 . Pre-amplification ranged from 40 to $60 \mathrm{~dB}$. The signal output from the pre-amplifier was connected (i.e. via BNC/coaxial cable) directly to a commercial data acquisition card. This acquisition card provided up to $8 \mathrm{MHz}$ sampling rate and incorporated 16-bit precision giving a dynamic range of more than 85 $\mathrm{dB}$. Prior to the analog-to-digital converter (ADC), the card employed anti-aliasing filters that can be controlled directly in software.

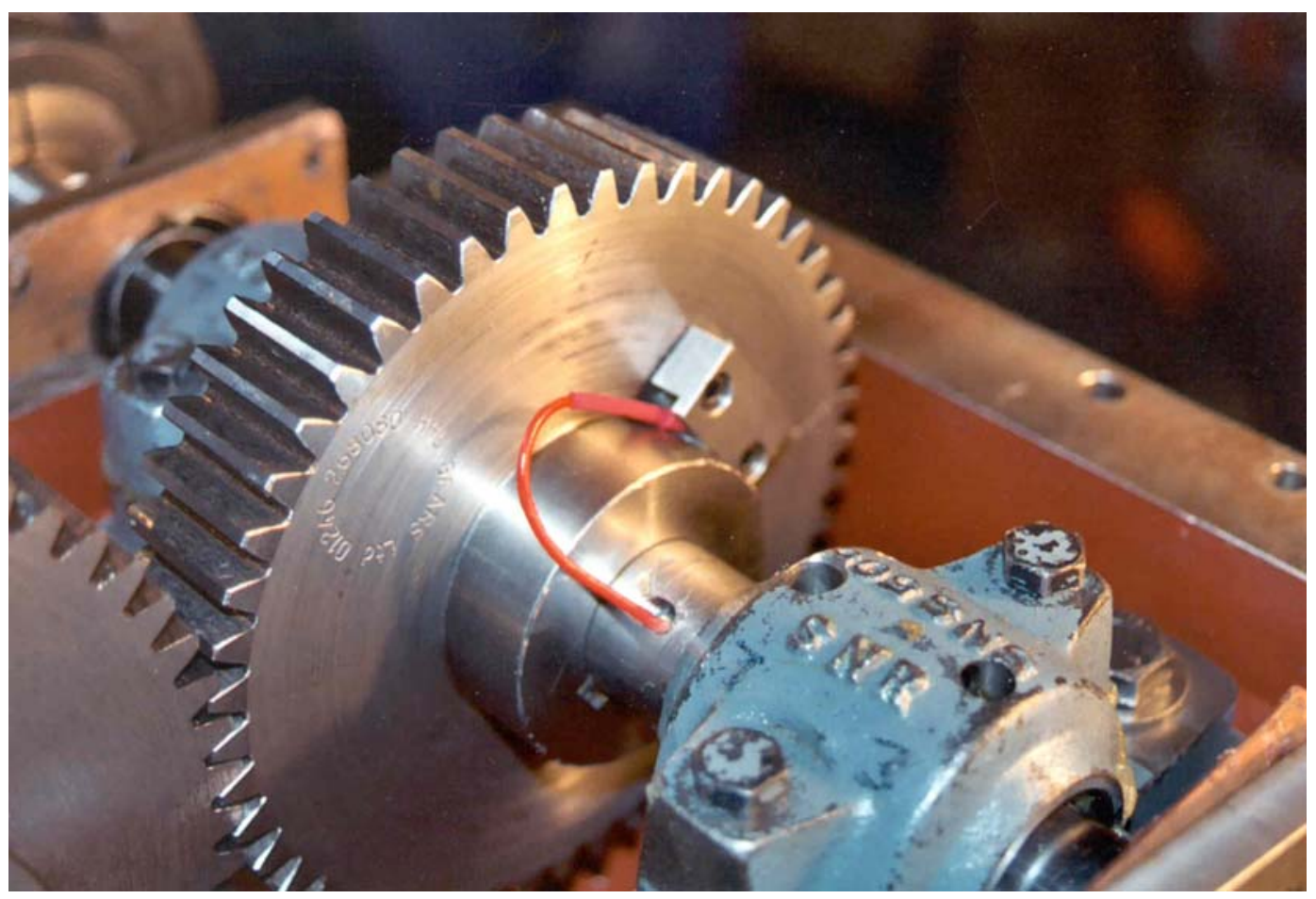

Figure 2 AE sensor located on driven wheel

Energy and r.m.s values were calculated in real time by the ADC controlling software. The software employed a hardware accelerator so that calculations could be performed in 
real time. The hardware accelerator takes each value from the ADC and squares it. The results are added into an accumulator for a programmable time interval, based on the user set time constant. At the start of the time interval the accumulator is cleared and at the end of the time interval the accumulator value is stored. The r.m.s is then calculated by taking the square root of the sum of the accumulated squared ADC readings. The energy value computed was equivalent to the area under time the waveform and is measured in Atto-Joules. The time interval for acquisition was set at $100 \mathrm{msec}$ and the graphical display presented in this paper was obtained by averaging 50 acquisitions; in effect, every point on the graph was equivalent to an average value over five-second of acquisition.

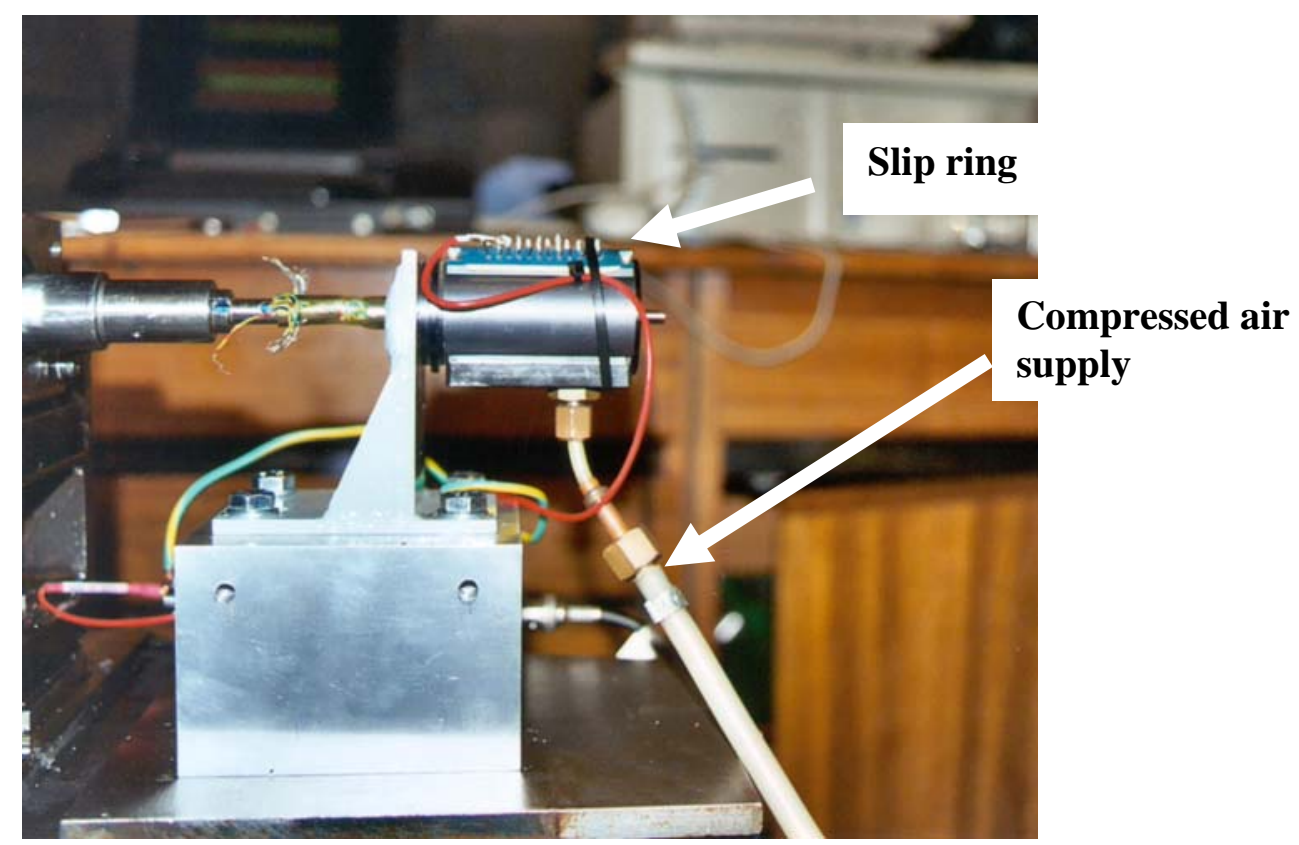

Figure $3 \quad$ Slip ring with compressed air supply

Prior to taking data on the gearbox test-rig the gear sets were run-in for over four hours at rotational speed of between 300 to 600rpm. AE background noise was monitored at three 
rotational speeds, 600, 1300 and 1800rpm. In addition, observations of AE activity due to misalignment and natural pitting are detailed.

\section{Observations and discussions on background noise}

During tests AE background noise measurements for defect free gears were recorded. Three speeds at a fixed torque were investigated and the results, with the sensor placed on the driven wheel and the bearing casing of the driven wheel shaft, are detailed in figures 4 to 7.

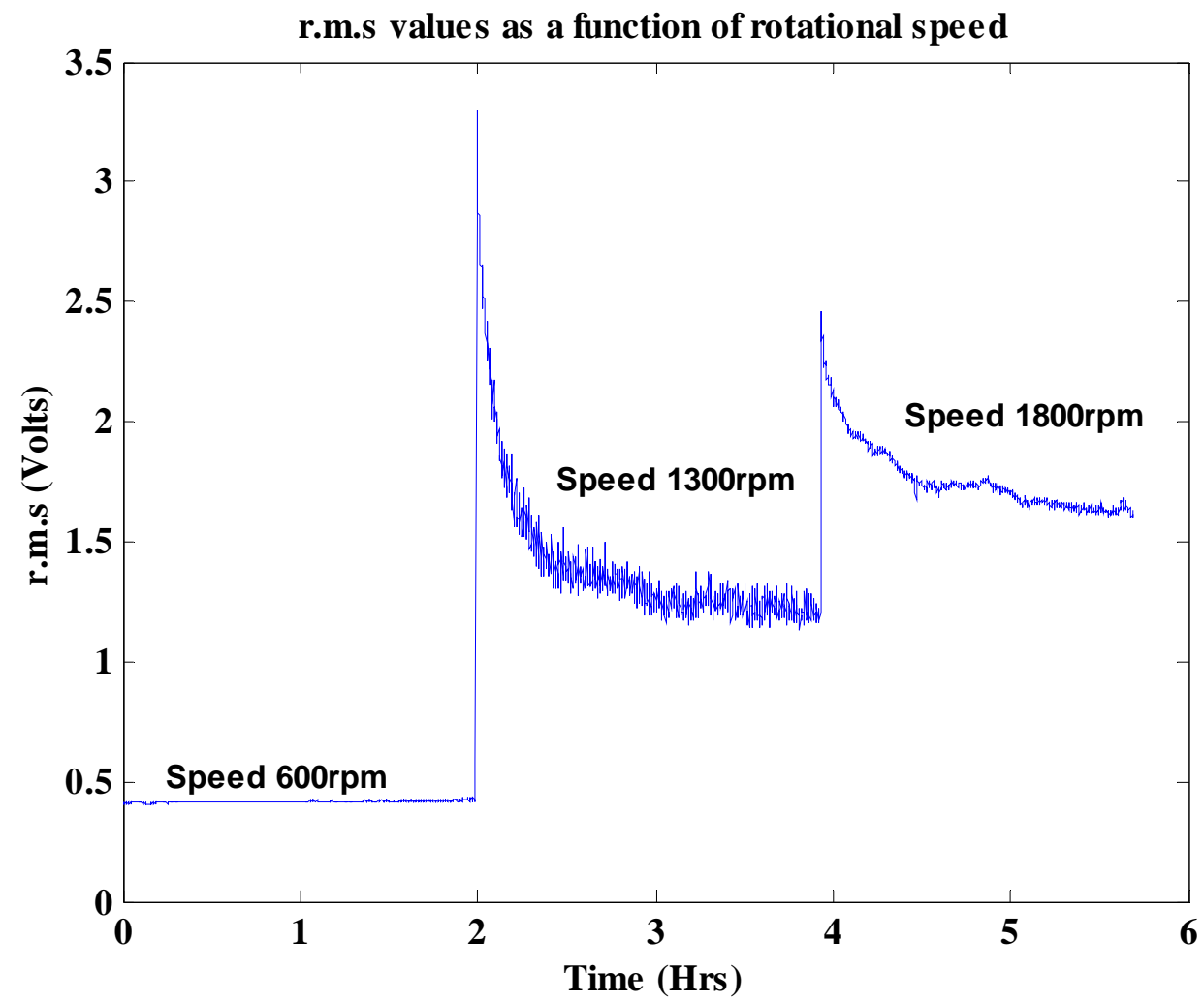

Figure 4 Relationship between AE r.m.s and speed for background noise with sensor on the driven wheel 
NDT and E International, 36 (7), pp. 471-477, 2003

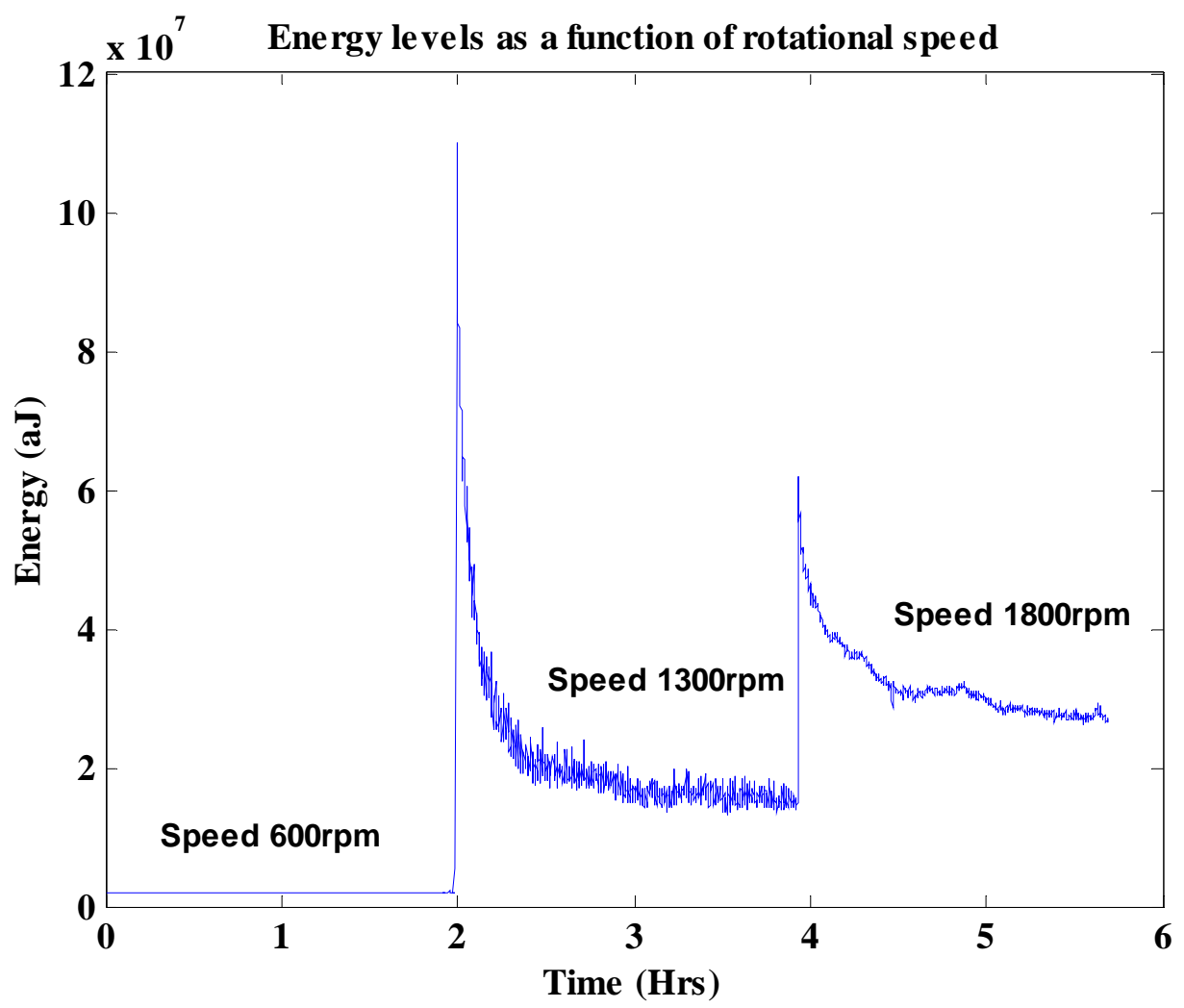

Figure 5 Relationship between AE energy and speed for background noise with sensor on the driven wheel 
NDT and E International, 36 (7), pp. 471-477, 2003

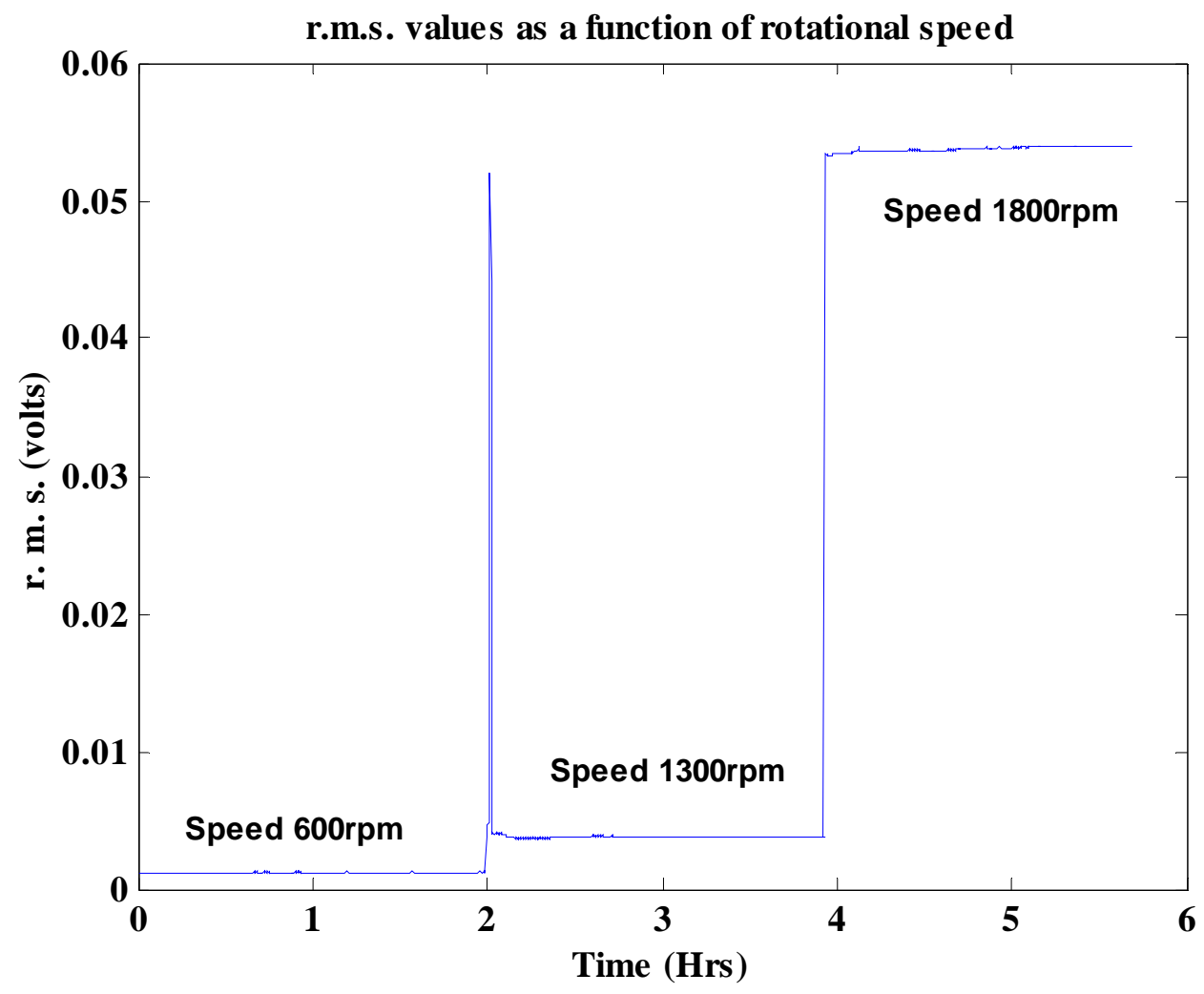

Figure 6 Relationship between AE r.m.s and speed for background noise with sensor on the driven wheel bearing casing 
NDT and E International, 36 (7), pp. 471-477, 2003

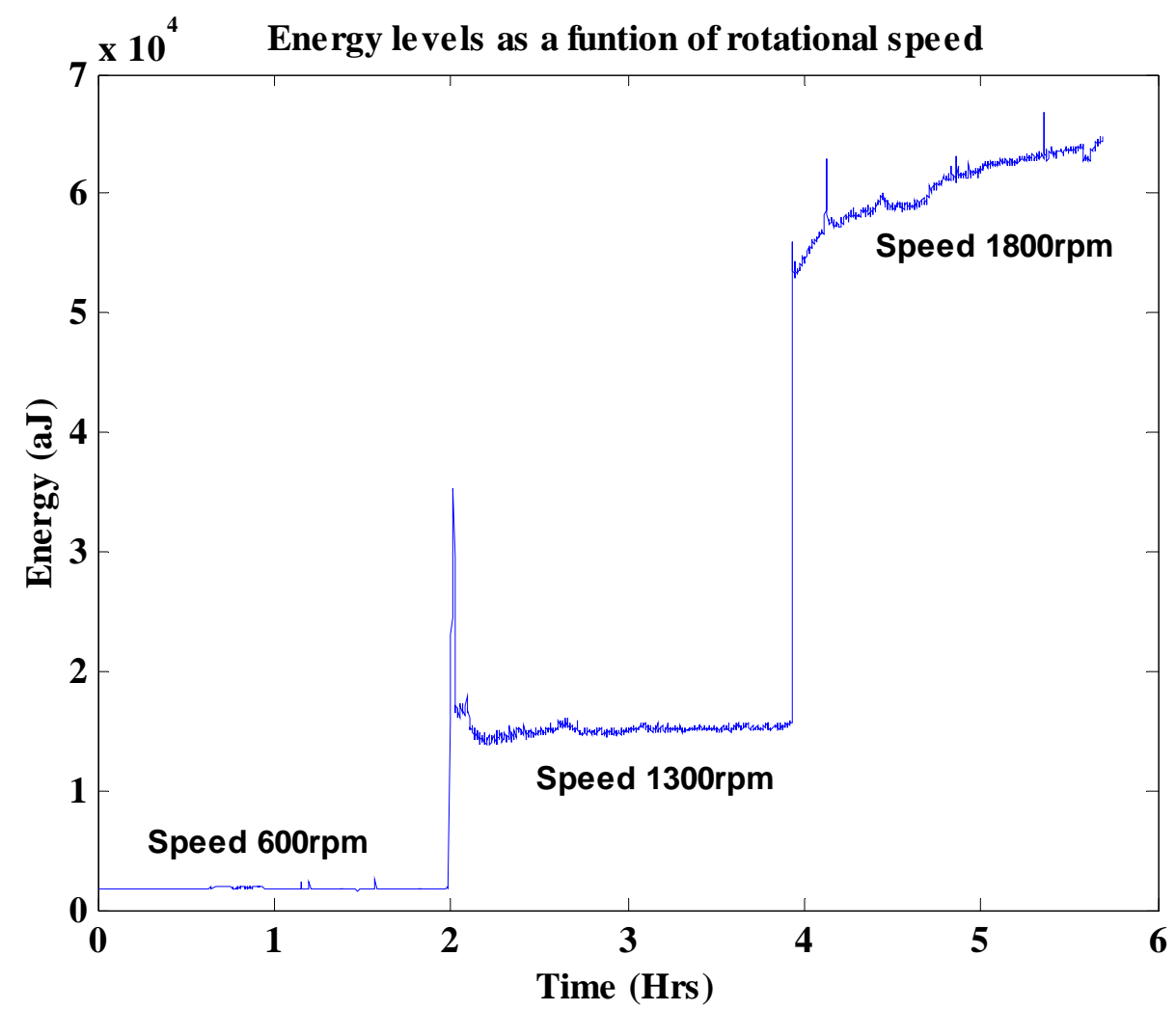

Figure $7 \quad$ Relationship between AE energy and speed for background noise with sensor on the driven wheel bearing casing

Clearly, it was evident that increasing the rotational speed resulted in an increase in $\mathrm{AE}$ r.m.s and energy values irrespective of the location of the AE receiving transducer. The difference in levels of AE r.m.s and energy due to the position of the receiving sensor was attributed to attenuation. Furthermore, whilst a change in speed resulted in a relatively instanteneous significant increase in AE r.m.s and energy value, a gradual decrease in these values to an underlying base level was observed. 
This gradual decrease was more evident with $\mathrm{AE}$ data capatured from the driven gear wheel. It was also noted that for the sensor placed on the driven wheel, the AE r.m.s and energy values associated with a rotational speed of 1300rpm showed relatively more activity that at other speeds, see figures 4 and 5. This was attributed to the fact that resonance of the geared system, which was approximately 1150rpm, generated larger excitations of the system, resulting in an increase in $\mathrm{AE}$ variation about a mean value. Whilst these results are in agreement with Singh [12], this is the only publication that shows the instantaneous effect of change in speed on $\mathrm{AE}$ values in real time on a gearbox. Clearly, it suggest that whilst changes in operating conditions result in changes of AE parameters, there is a gradual 'settling in' period in which the measured AE values decrease to a base level, albeit higher or lower than the previous process condition. The gradual settling period is attributed to the gearbox reacting and accommodating the change in dynamic characteristics.

\section{Observations and discussions on misalignment}

Whilst undertaking experimental tests a set of gears was replaced and background noise readings were undertaken prior to continuing with the investigative programmes scheduled. At 1300rpm, following the instantaneous rise in AE r.m.s and energy, the AE values gradually decreased as had been observed earlier (see section 3). However, just as the $\mathrm{AE}$ values were showing indications of reaching a base level, the values began to rise

and trend upwards, see figures 8 and 9. The authors continued the experiment and 
monitored the AE activity. After approximately 6-hours of continuous running and data acquisition, it was thought prudent to pause the acquisition system and inspect the gear sets. This was accomplished by removing the gearbox case only. Evidence of pitting and scuffing were visible, see figures 10 and 11, all of which were indications of misalignment. The authors, having observed this, replaced the gearbox case and continued to run the test-rig and acquire AE data. The rig was paused for approximately one hour in total. Following reassembly the rig was restarted at 1300rpm and the acquisition system armed. A reduction in AE r.m.s and energy values were observed initially, see figures 10 and 11 , but it was very interesting to note that these values gradually increased to values which did not detract from the initial gradient of increasing trend. This observation showed the AE values continued to rise irrespective of the pause in operation and vindicates the robustness of the technique for machine diagnosis.

Eventually the AE activity levelled off after 11 hours of operation. At this stage the gearbox speed was increased to 1800rpm for a short duration after which the gear was visually inspected. Increased pitting and wear were evident, see figure 12 . The settling of AE values after such a prolonged period of increase is attributed to the establishment of a constant rate of wear. It is worth noting that the levels of AE r.m.s and energy are greater with misalignment than observed for background noise under defect free condition. Sentoku's [10] findings that AE activity increased with increasing wear have been verified. In addition, it was observed that the rate of increase in $\mathrm{AE}$ values reached a maximum, and remained at this level for over four-hours. 
NDT and E International, 36 (7), pp. 471-477, 2003

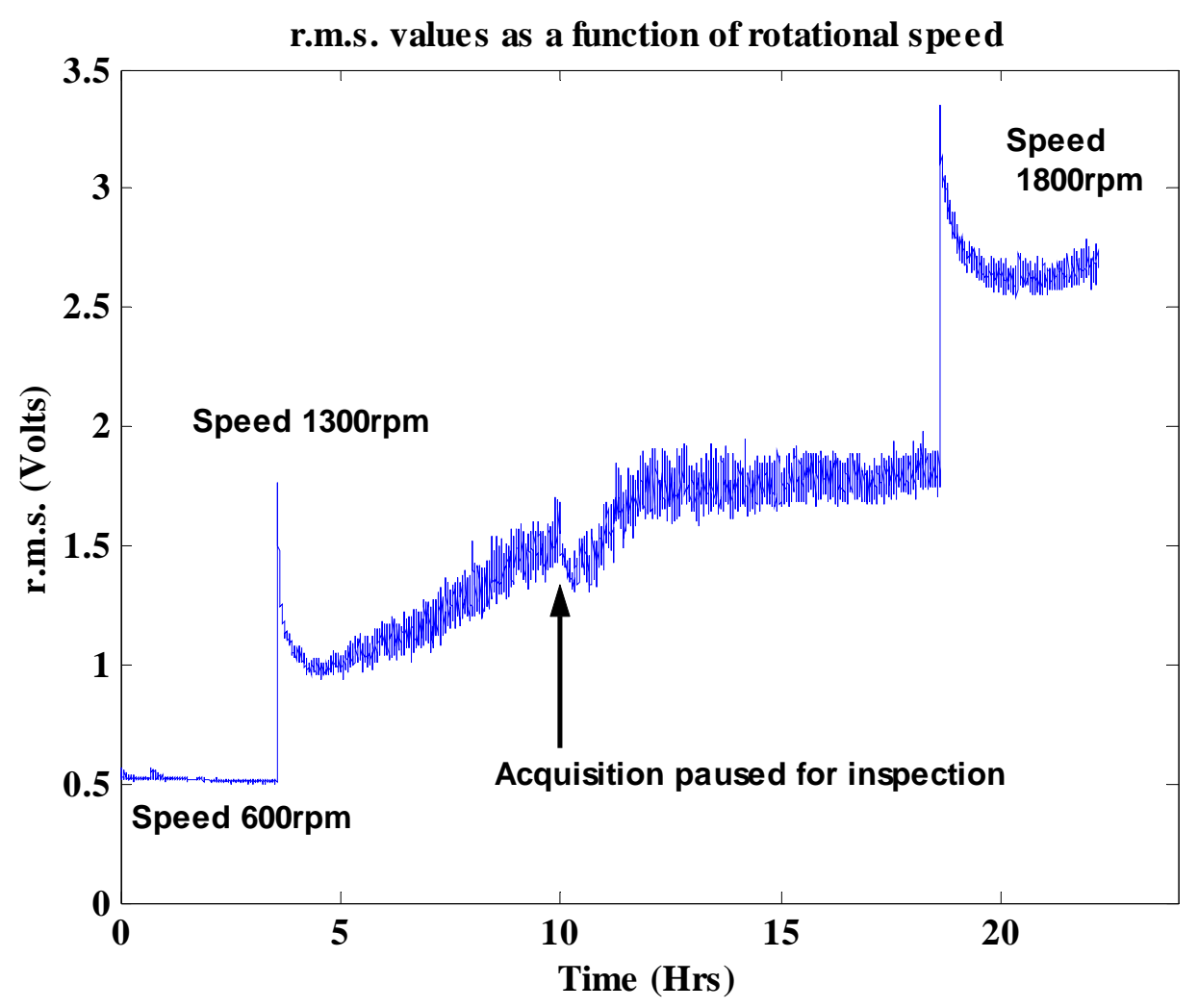

Figure 8 Observations of AE r.m.s as a function of speed with sensor on the driven wheel 
NDT and E International, 36 (7), pp. 471-477, 2003

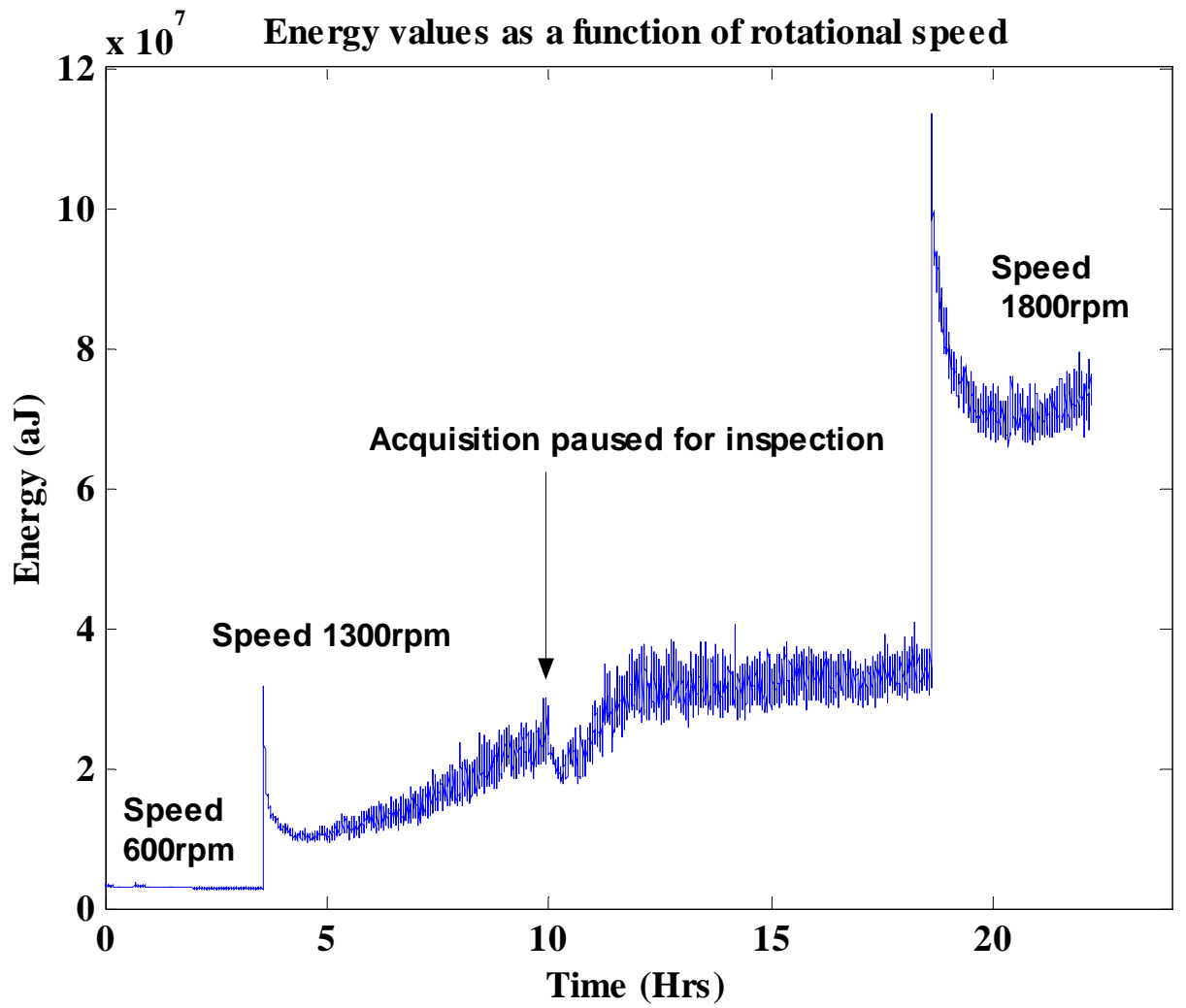

Figure 9 Observations of AE energy as a function of speed with sensor on the driven wheel 
NDT and E International, 36 (7), pp. 471-477, 2003

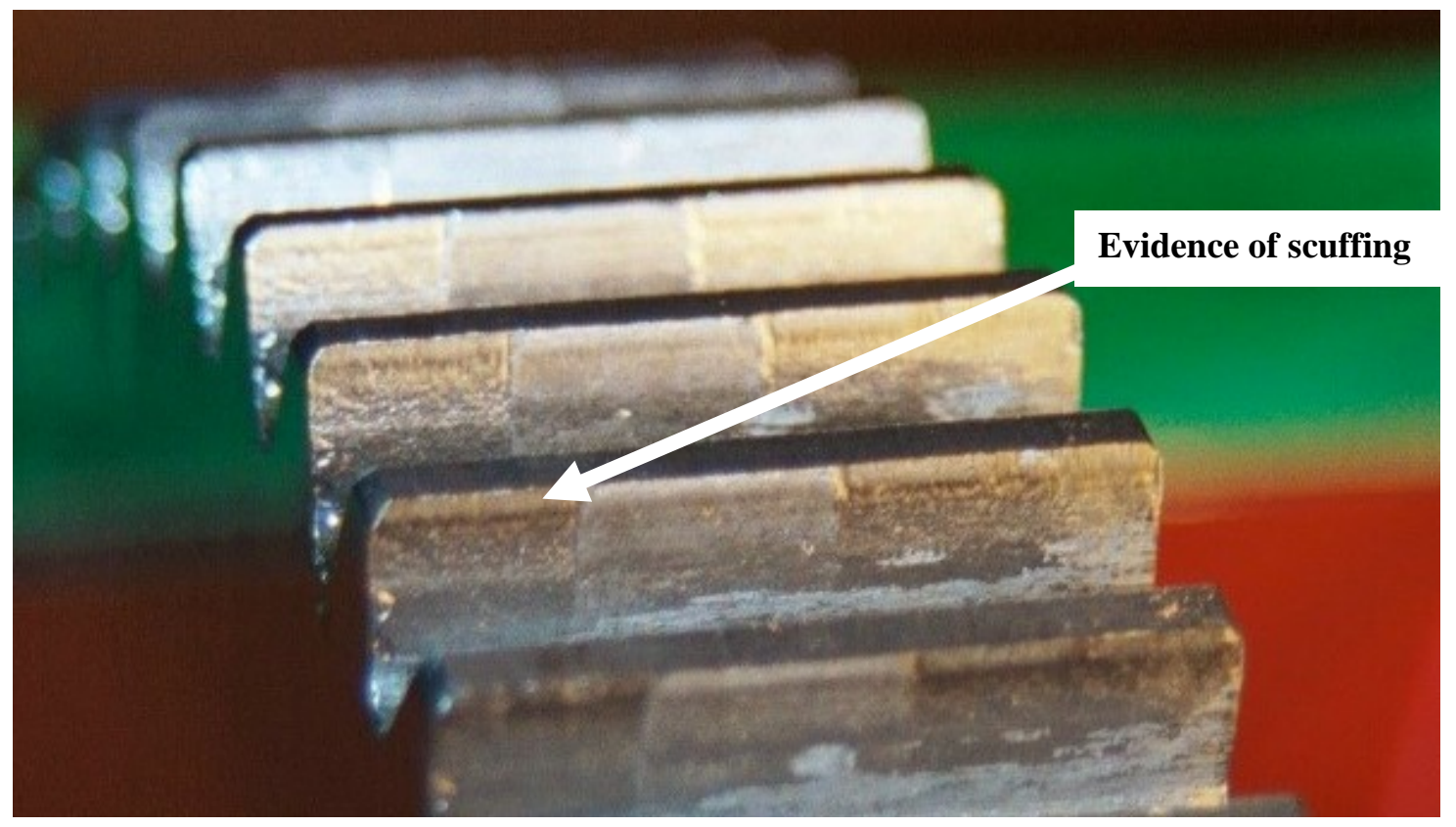

Figure 10 Observations of early stages of micro and macro pitting, and scuffing

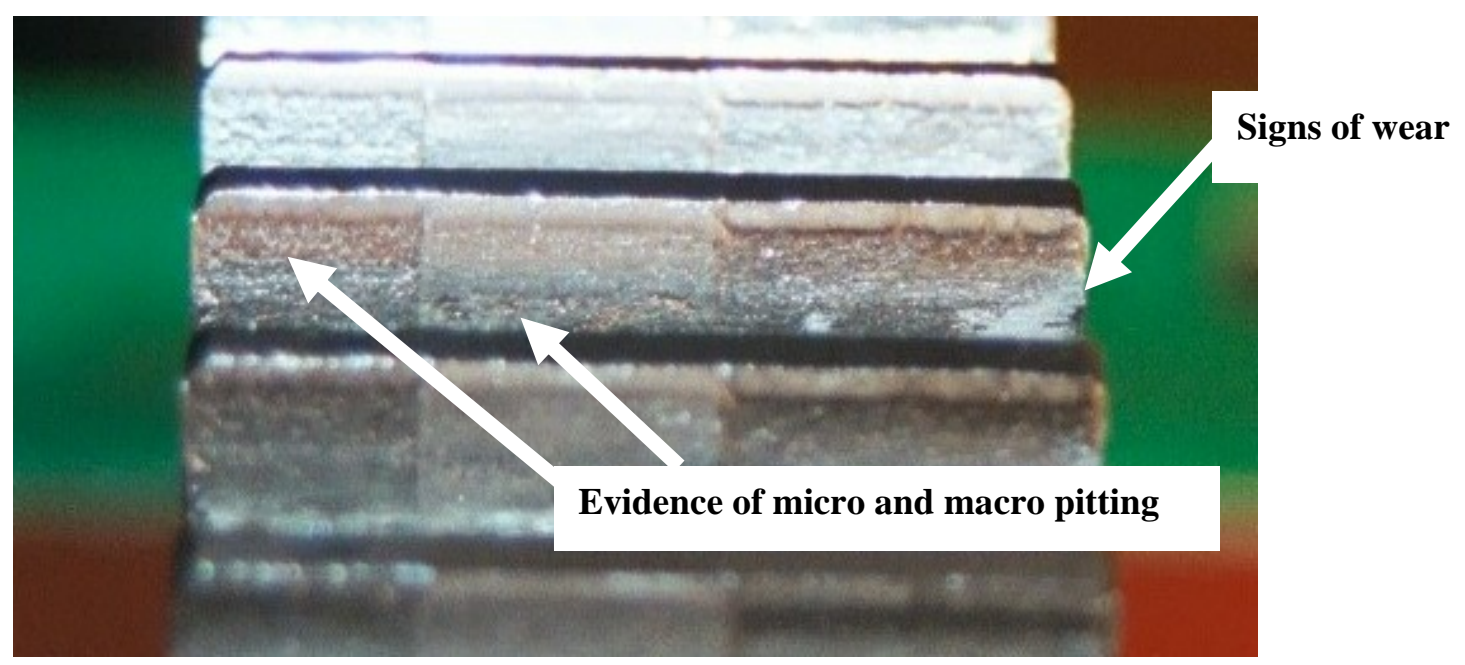

Figure 11 Evidence of micro and macro pitting, and wear 


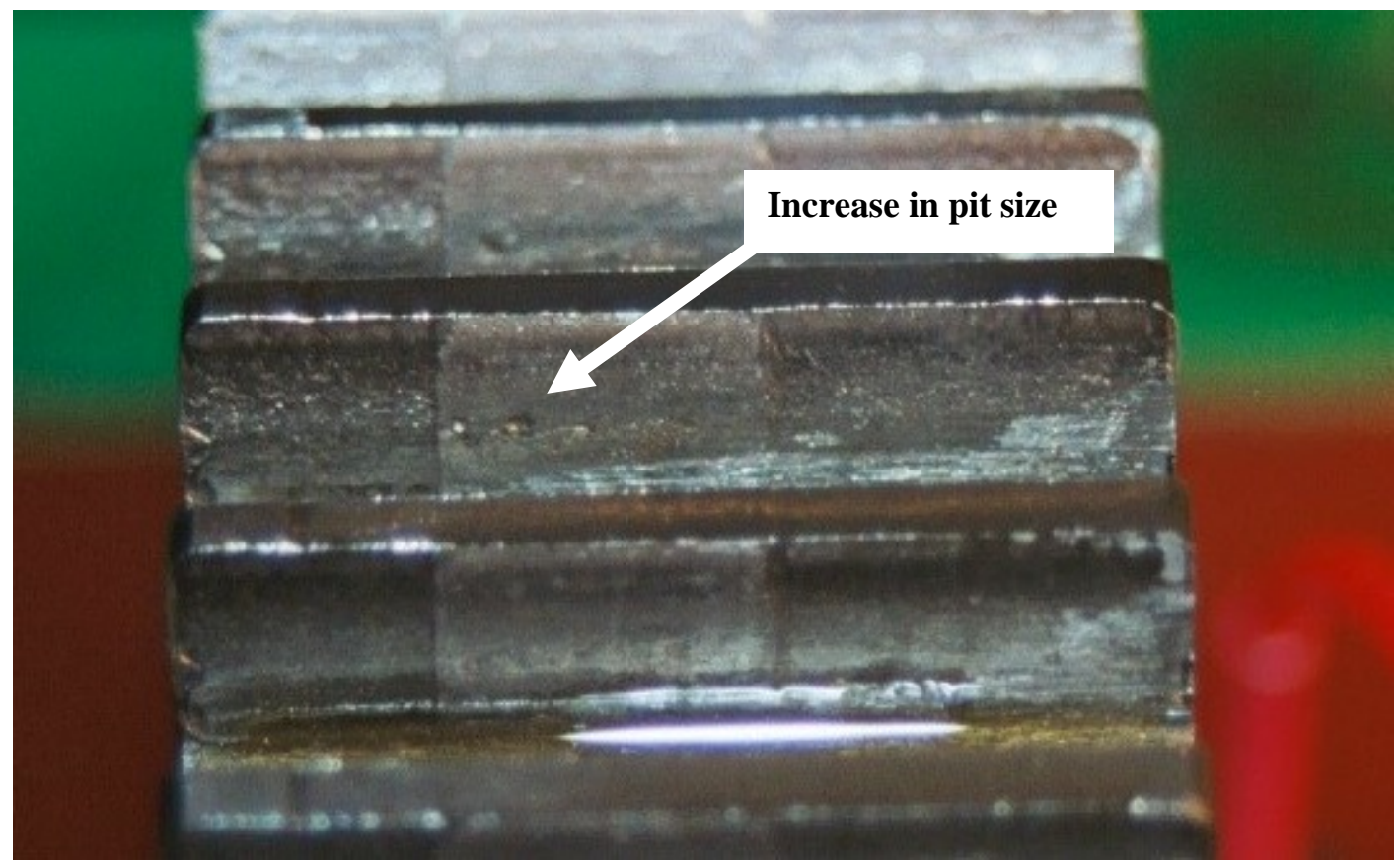

\section{Figure 12 Evidence showing further growth in pit size and wear}

In addition to the observations of misalignment detailed above in which the sensor was placed on the driven wheel, it was taught prudent to inspect AE r.m.s and energy values detected with the sensor on the driven wheel bearing housing, see figures 13 and 14 . It was noted that the gradual increase in AE parameters at 1300rpm, as detected with the sensor on the driven gear, was not evident. However, indications of drop and rise in $\mathrm{AE}$ r.m.s and energy are clearly evident when the acquisition system was paused to allow for inspection, see figures 13 and 14. It was also observed that unlike background noise, the AE r.m.s and energy values at 1300rpm showed spurious activity during the period of pit growth. 
NDT and E International, 36 (7), pp. 471-477, 2003

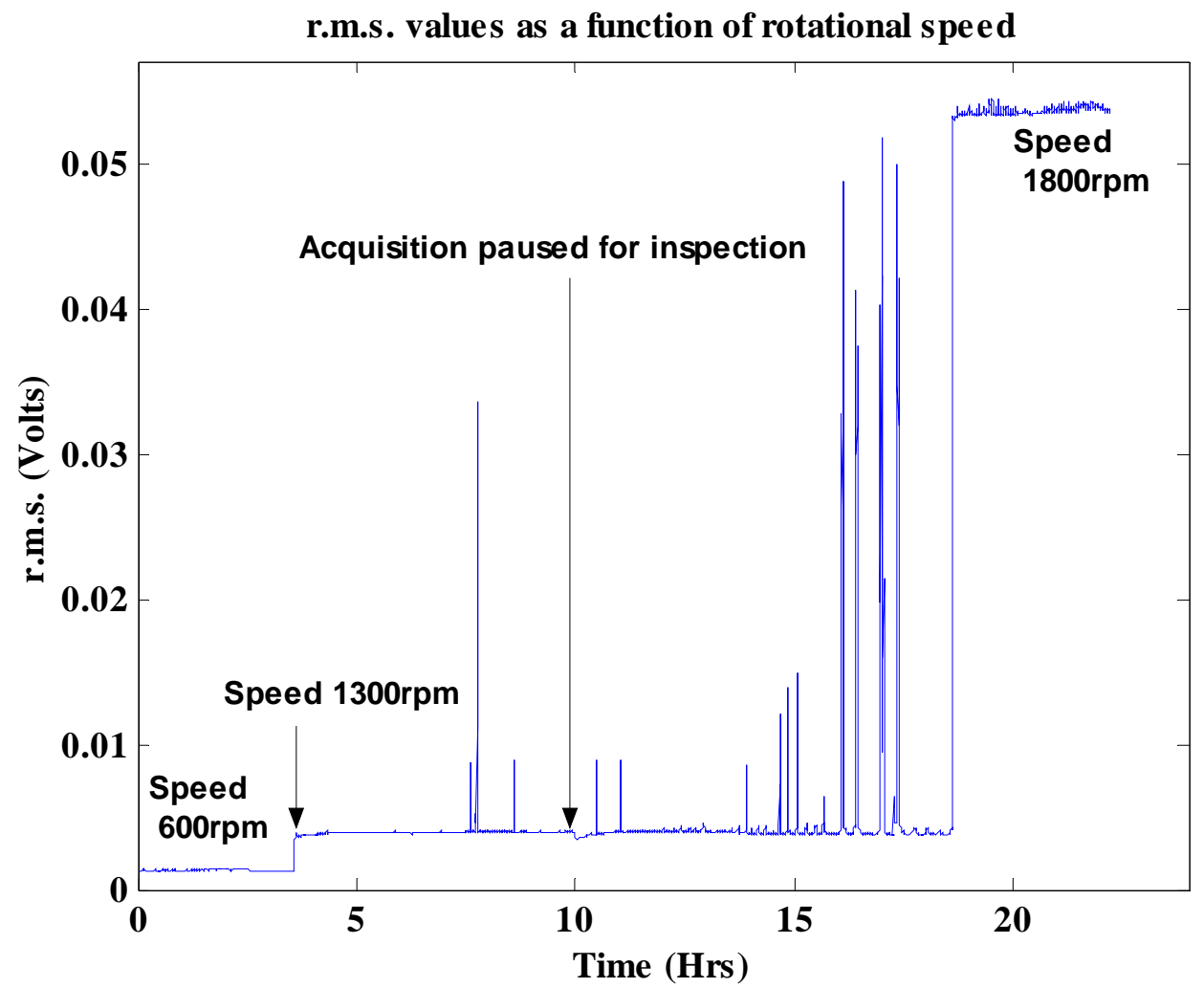

Figure 13 Observations of AE r.m.s as a function of speed with sensor on the driven wheel bearing casing 
NDT and E International, 36 (7), pp. 471-477, 2003

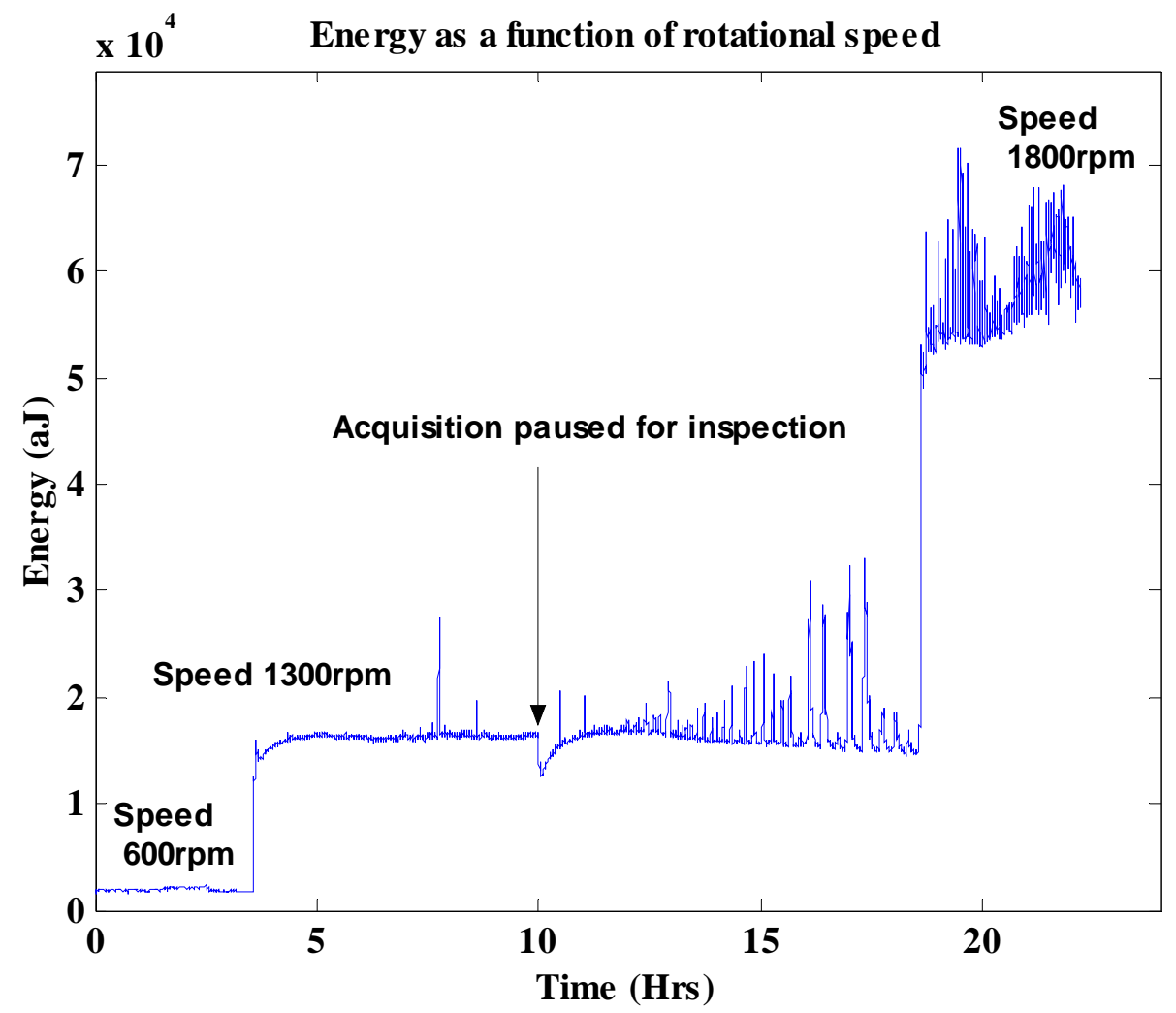

Figure 14 Observations of AE energy as a function of speed with sensor on the driven wheel bearing casing

\section{Conclusion}

This paper has demonstrated the applicability of AE to gear health diagnosis. The behavior of $\mathrm{AE}$ to changes in speed or process in real time has been presented. Furthermore, it has been demonstrated that gear defect can be diagnosed from the bearing casings. Results of this ongoing work will be subject to future publications. 


\section{References}

1. Sato (1990), "Rotating machinery diagnosis with acoustic emission techniques", Electrical Eng Japan, 110(2), pp. 115-127

2. D. Mba, R. H. Bannister (1999), “Condition monitoring of low-speed rotating machinery using stress waves: Part1 and Part 2”, Proc Inst Mech Engrs, Vol 213, Part E, pp 153-185.

3. T. Holroyd and N. Randall (1992), "The Use of Acoustic Emission for Machine Condition Monitoring”, British Journal of Non-Destructive Testing, vol. 35(2), pp 75.

4. The detection of shaft-seal rubbing in large-scale turbines using acoustic emission. 14th International congress on Condition monitoring and Diagnostic engineering management (COMADEM'2001) Manchester, UK, 4-6 September 2001, Hall L, Mba D.,p 21-28, ISBN 0080440363

5. D. Mba, Applicability of acoustic emissions to monitoring the mechanical integrity of bolted structures in low speed rotating machinery: case study. NDT and E International. Vol 35, No. 5, pp. 293-300. 2002

6. Drosjack, M. J and Houser, D. R., An experimental and theoretical study of the effects of simulated pitch line pitting on the vibration of a geared system. ASME publication. Report 77-DET-123, 1977.

7. Olver, A. V., Gear lubrication - A review; Proc. Instn Mech. Engrs, Vol 216, Part J, Journal of Engineering Tribology, 255-267, 2002. 
8. Al-Balushi, K. R., and Samanta, B., Gear Faults Diagnosis Using Energy-Based Features of Acoustic Emission, Proc. Instn Mech Engrs, Journal of Systems and Control Engineering, Vol 216, Part I, 249-263, 2002.

9. Tandon, N. and Mata, S., Detection of Defects in Gears by Acoustic Emission Measurements, Journal of Acoustic Emission, Vol. 17, Issue 1-2, 23-27, 1999.

10. Sentoku, H., AE in Tooth Surface Failure Process of Spur Gears, Journal of Acoustic Emission, Vol. 16, Issue 1-4, S19-S24, 1998.

11. Miyachika, K., Oda, S., and Koide, T., Acoustic Emission of Bending Fatigue Process of Spur Gear Teeth, Journal of Acoustic Emission, Vol. 13, Issue 1-2, S47-S53, 1995.

12. Singh, A., Houser, D. R., and Vijayakar, S., Early Detection of Gear Pitting, Power Transmission and Gearing Conference, ASME, 1996, DE-Vol. 88, 673678.

13. Singh, A., Houser, D. R., and Vijayakar, S., Detecting Gear Tooth Breakage Using Acoustic Emission: A Feasibility and Sensor Placement Study, Journal of Mechanical Design, Vol 121, 587-593, 1999. 